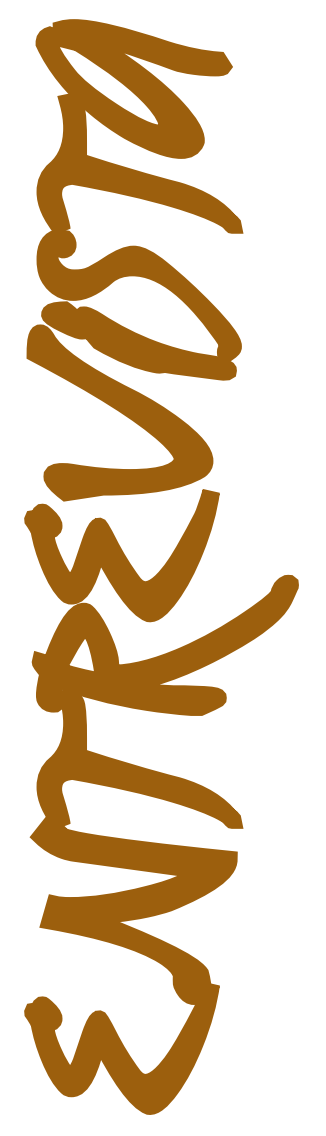

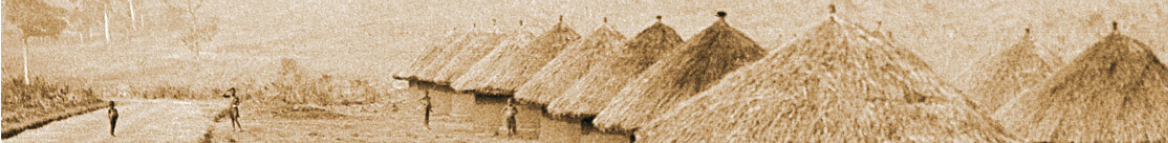

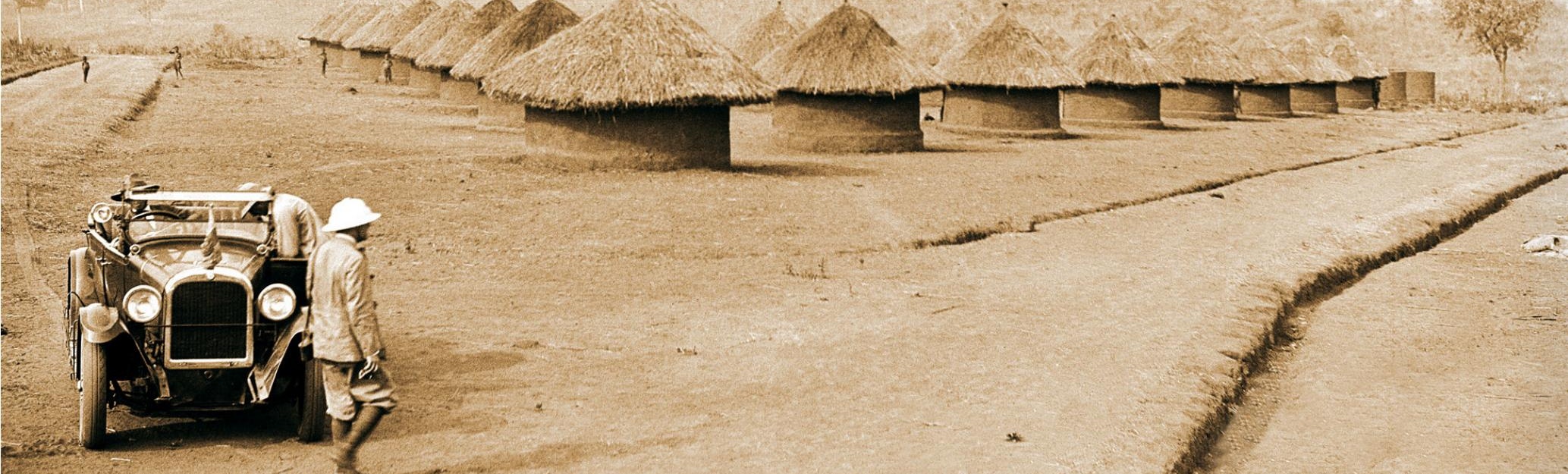




\title{
NO ROSSIO, CAFÉ SUÍÇA, UMA VIA- GEM NO TEMPO NA COMPANHIA DE FRADIQUE MENDES
}

\author{
Por Eduardo Gonzales Moreira \\ (Universidade de São Paulo)
}

\section{ENTREVISTA COM FERNANDO VENÂNCIO}

Fernando Venâncio é um escritor e crítico literário português. Atualmente, trabalha na Universidade de Amsterdã e tem nacionalidade holandesa. É autor e colaborador regular de revistas portuguesas de prestígio como Jornal de Letras, Ler e Colóquio/Letras, e trabalha como crítico literário. Ele também publica no jornal Expresso e na revista Visão. Até março de 2008, foi colaborador regular do blog coletivo "Aspirina B".

Em um dia nublado, 11 de janeiro de 2011, terça-feira, após conhecer a cidade branca, tive a feliz oportunidade de entrevistar o autor da obra Os Esquemas de Fradique, o prof. Dr. Fernando Venâncio. Marcamos às 16 horas em um dos cafés mais tradicionais da cidade, o Café Suíça, situado no Rossio, área central de Lisboa.

Eduardo Moreira: Carlos Fradique Mendes é, sem dúvida, uma das personagens mais enigmáticas da literatura portuguesa, ou posso dizer da literatura mundial, um misto de homem, gênio, pecador. O senhor poderia citar algumas poucas características legitimamente portuguesas que essa personagem carrega, e se carrega?

Fernando Venâncio: Creio que uma das graças de Fradique é que exatamente tem muito pouco da figura do português. É alguém que acumula durante a sua vida várias existências, sendo impossível que pudesse fisicamente fazer tudo o que ele fez. Nem viveu muito, morreu com cinquenta e poucos anos. E, no entanto, ele teria visitado praticamente tudo no mundo, menos a África austral e o Brasil, onde o romancista José Edu- 
ardo Agualusa o leva, no romance Nação Crioula. Nesse sentido, o Agualusa ainda junta a impossibilidade que o Eça descreve com outra impossibilidade. Fradique contactou com toda a gente importante que havia no mundo, leu tudo o que havia de importante pra ler, o que é muito, aprendeu uma porção de idiomas, e ainda tinha tempo para a sua existência de dândi, com as suas aventuras, com seus esportes. Nesse sentido, ele poderia no máximo ser um inglês com umas tintas francesas, tintas de italiano, mas português muito pouco. Eu não tenho a certeza do que vou dizer, mas podíamos suspeitar que o Eça fez dele alguém que exatamente não poderia ser português. E, no entanto, era português. Honra-nos muito. Fradique seria o melhor de nós. O melhor no sentido neutro, portanto, a melhor parte de nós, e também o melhor indivíduo português pensável. E talvez essa não só impossibilidade de ele existir como pessoa, mas também a sua não portugalidade, talvez tudo isso faça parte do jogo mental que o Fradique é. Sim, é um jogo mental do Eça. Há quem entre pela simbologia e diga que é uma espécie de compensação do Eça, que sempre teria tido um complexo de inferioridade, ao ser um filho ilegítimo. Não é necessário entrar por aí. A genial construção daquela figura já enche todas as medidas.

E. M.: O senhor acredita que o fato de esta personagem ter sido criada tendo como forma o gênero epistolar, isso deu margem para as efabulações? Ou seja, o senhor acredita que o caráter lacunar temporal da carta pode ter também promovido isso?

F. V.: Creio que você tem uma intuição formidável ao fazer a ligação entre o caráter lacunar da carta e a figura de Fradique Mendes. Acho que nunca ninguém fez essa conexão. Meus parabéns! Digamos que escrever em cartas é talvez a maneira mais fácil de fazer ficção. É uma impressão muito forte que tenho, e tenho-a há muito tempo. Se alguém não soubesse como escrever um romance, nós poderíamos dar-lhe o conselho: "Escreve cartas. E faça por essas cartas o romance”. A carta presta-se muito à efabulação. Isso é uma convicção muito forte minha, só que não sei racionalizar a questão. Mas é mais fácil pra efabular inventando uma carta do que inventando um episódio. A sua intuição é também valiosa no sentido da própria figura do Fradique, de que nunca se poderia dar uma ideia genérica e atender por completo. Claro que o prefácio que o Eça escreveu sobre Fradique Mendes, que é um autêntico romance, que ele chama Notas e Comentários, que é a vida de Fradique Mendes, isso é uma biografia, simplesmente é uma biografia dos contatos entre eles. Porque naquilo que o Fradique fez, naquilo que ele viajou, naquilo que ele empreendeu, o Eça é muito sucinto, dá exemplos picantes, exemplos que falam à imaginação, mas não aprofunda, ele não investe em uma viagem concreta, numa iniciativa concreta. A única viagem que eu recordo que é contada com pormenores nessa "Introdução" de A Correspondência de Fradique Mendes é a viagem ao Oriente, que o próprio Eça fez. Portanto, quando Eça e Fradique contactam, Eça esteve nessa informação, nos episódios. Quanto à própria biografia do Fradique, só Fradique, nós só sabemos em traços largos: fez viagens, contactou com 
muitas pessoas, não foi ao Brasil, não foi à África Austral e, portanto, há imensas lacunas na biografia de Fradique Mendes, só Fradique Mendes. E, portanto, o gênero epistolar se enquadra muito bem com essas lacunas, mais uma vez a sua intuição. Exatamente esse tipo de vida pouco preenchida permite a continuação da ficção. E repare que a ficção já começa muito cedo. Poucos anos depois da morte do Eça, em 1900, aparece já a primeira ficção sobre Fradique. Faço referência a ela num livro chamado Objetos Achados, onde está um capítulo acerca da ficção sobre Fradique Mendes. E aí indico a primeira, feita por João Chagas, que em 1908 escreve uma carta ao filho de Fradique Mendes. É a primeira ficção pós-queirosiana.

E. M.: Um discurso em camadas, acredito que há até se chegar ao último Fradique. Um personagem que é formado pelos discursos de vários autores. O senhor acredita que há uma coerência no processo de formação dessa personagem no decorrer do tempo?

F. V.:- Tenho impressão que sim. Não sei se por casualidade ou por uma razão intrínseca da figura. Se há alguma coisa em comum entre todas essas ficções, é realmente o fascínio que a figura recolhe, concita, estimula, cria. Algumas ficções são melhores do que outras. Por exemplo, a ficção daquele livro, O único filho de Fradique Mendes, é relativamente fraca. Mas foi construída por um rapaz aos 16 anos, e nessa idade as capacidades de efabulação não são as mais fortes. Isso pra dizer que há muitas diferenças na efabulação da figura de Fradique. Isso cria diversidade, talvez isso também possa ser uma vantagem, não sei. Mas o que há é sempre esse gosto imenso de pegar nessa figura e continuar a dar-lhe vidas. O Fradique de Agualusa tem um lado biográfico, digamos. Dá a ele um determinado tipo de existência. Mas as outras histórias acontecem já depois da "morte" de Fradique. E mesmo o meu romance só tem Fradique ao princípio, como acompanhante da princesa Rattazzi que vem visitar Portugal, um fato real, o que é ficção é Fradique a acompanhar a princesa. Digamos que há o Fradique ainda vivo, e há o Fradique que já não vive histórias da sua existência. No primeiro caso, do filho, no segundo caso do Agualusa, uma filha, e no meu caso um neto e uma neta.

E. M.: Especificamente o Fradique de Agualusa, a meu ver, é tomado de empréstimo com o objetivo de transgredir o Fradique queirosiano, mostrando uma outra face deste ser. A meu ver ao mesmo tempo em que transgride, homenageia e até mesmo fortalece o Fradique queirosiano, pois somente essa personagem poderia ter força, coragem e excentricidade o suficientes para se aventurar na Europa, na África e no Brasil. O que o senhor pensa sobre isso?

F. V.: A sua pergunta é perfeita. E eu não poderia responder melhor do que repetir o que você disse. Acho que você tem também uma intuição magnífica e que só ganha em desenvolvê-la.

E. M.: O senhor acredita, assim como eu, que o mote Fradique Mendes é inesgotável? Também por se tratar, de certa maneira, de um personagem moderno e principalmente mutável? 
F. V.: Estou totalmente de acordo. Eça construiu de maneira que ele é inesgotável. Temos um ponto de vista positivo e um ponto de vista negativo. Do ponto de vista negativo digamos que Eça não o descreveu totalmente, deixou muita margem à imaginação e à imaginação posterior, mas também do ponto de vista positivo no sentido de que ele foi criado sobre uma fórmula inesgotável. Ele é construído pra ser inesgotável, pra reunir realmente toda a humanidade, toda a possibilidade do homem culto da segunda parte do século XIX. Ele é uma espécie de enciclopédia, tanto naquilo que faz como naquilo que conhece. Realmente tudo o que fez é importante. Ele contactou com pessoas importantes, ele reúne toda a humanidade, toda a sede da humanidade em potência, e nesse sentido o molde de que ele foi feito, a fórmula "Fradique Mendes", é inesgotável.

E. M.: O livro do senhor, Os Esquemas de Fradique, e o livro de José Antônio Marcos, O Enigma das cartas inéditas de Eça de Queiroz, colocam a todo o momento a questão entre a tênue fronteira entre realidade e ficção. Essa argumentação faz com que a história de Fradique fique mais provocante?

F. V.: Essa mistura de realidade e ficção é muito convidativa, na verdade é a fórmula da ciência e ficção, ou ficção-científica. Há sempre uma componente atual, portanto, reconhecível, e há uma componente irreal, que é imaginária. Se uma ficção científica fosse só, só imaginária, não funcionaria. Descrever uma guerra mundial de robôs é pensável, mas não é a melhor ficção-científica. Ora, o Eça, ao construir a figura de Fradique Mendes, ele está a fazer essa mistura que nós diríamos até que tem uma parte ou espécie de atualidade, porque se há coisa que pode dizer-se sobre essa fusão entre realidade de ficção é que é muito pós-moderna. Nesse sentido, tudo o que fez imaginar uma realidade paralela, como é o caso de Fradique Mendes, ele é uma realidade paralela, e não somente ficção, ele não é uma figura de ficção, é uma figura de "realidade paralela", porque é um confidente, um amigo, de alguém real, do próprio autor que descreve a história. Portanto, Eça cria uma espécie de biografia paralela à sua, e isso é muito, muito pós-moderno. Uma das características do pós-modernismo é tornar indestrinçável, em uma narrativa, a realidade e a ficção. Eça cria uma literatura que está a cem anos de distância, e, no nosso tempo, ainda muito viva e muito explorada até nos romances históricos, que são históricos porque as circunstâncias são reais, mas em que há uma personagem de ficção. É também uma fórmula formidável e é diante dessa fórmula que o Fradique é construído. Diretamente uma pessoa de realidade, uma realidade absolutamente tangível, mas ele de fato não existe.

E. M.: Há algo em comum para o senhor entre "as grandes navegações", "o sebastianismo" e Fradique Mendes?

F.V.: Essa é muito boa. Digamos que são três grandes invenções portuguesas. E pelo visto os portugueses têm muita capacidade de imaginar. As descobertas foram imaginadas antes de serem realidade, e elas fo- 
ram acompanhadas de bastante ficção, ou ao invés de dizer ficção podemos dizer narrativa, e há ótimas narrativas das descobertas, por exemplo, a História trágico-marítima e Os Lusíadas, isso está entre 1500 e 1572. Digamos que as descobertas portuguesas já foram acompanhadas de narrativas. $\mathrm{O}$ sebastianismo é também uma narrativa ideológica, que os portugueses dos séculos XVI e XVII contam a si próprios pra se aguentarem nas adversidades, e no fundo pra não se frustrarem, pra conservarem até um pouco de positividade de sua autoimagem. "Nós estamos em uma situação tremenda, sem nobreza, sem dinheiro, sem rei, mas Sebastião vai voltar". O Fradique é também uma narrativa ideológica. Digamos que há uma mensagem subliminar do Eça, que é: "Nós, portugueses, somos uma desgraça, péssimos numa porção de coisas. Mas imaginemos que nós éramos um Fradique”. Fradique recolhe, portanto, tudo aquilo que os portugueses deveriam ser, deveriam poder ser e não são. Eu estou a dizer isso e estou a pensar em outra coisa que tem também um pouco a ver com o Eça. Trata-se de um amigo dele, o Ramalho Ortigão. O livro mais famoso dele, A Holanda, é uma história, uma descrição de viagem de Ramalho à Holanda por ocasião de uma Exposição Universal. Mas toda a clara intenção do livro é descrever a Holanda como um espelho pra Portugal: "Vejam o que esse país faz, o que esse país consegue". É uma visão de direita, uma visão conservadora, Ramalho era realmente uma figura de direita, de uma direita imensamente educada, muito consciente e orgulhosa de si. O país era nesse tempo, nesses anos 80, 90, um caos. E então Ramalho apresenta a Holanda, apresenta a ordem que existia na Holanda, o desenvolvimento que existia na Holanda. Tudo isso é uma mensagem: "Meus caros compatriotas, vejam, esse país existe. Esse país é possível aqui." Nesse sentido, há o autêntico paralelo entre A Holanda do Ramalho e o Fradique Mendes do Eça. Ambas são narrativas ideológicas, com uma intenção civilizadora, educacional muito clara. Penso que talvez nunca ninguém tenha feito esse paralelo.

E. M.: Ao meu ver, Fradique nasce contestador e destemido, depois toma ares de garoto propaganda e de personagem muitas vezes sentimental com Agualusa. O seu Fradique, mesmo que ele seja retomado pela lembrança das personagens no romance, o que é o seu Fradique? Como o senhor definiria a imagem dessa personagem em sua obra, mesmo que o senhor não a tenha criado fisicamente?

F. V.: É um fato: eu não criei o Fradique. O “meu” Fradique tem alguma elaboração pós-queirosiana, mas aproveito o mais possível o Fradique já criado pelo Eça. Portanto, não tenho qualquer intenção de explorar a figura do Fradique, porque já havia a exploração queirosiana, e já havia a exploração agualusiana, e essas são duas criações magníficas. Não senti qualquer necessidade de imitá-los nesse sentido. Eu tinha toda uma história atual pra contar, mas tinha alguma necessidade, também, de fazer um trabalho de ensaio. Há uma componente de ensaio no meu romance, eu reconheço isso, e isso torna um romance difícil de ler. Vamos dizer, é para os bons provadores. Isso faz com que o romance nunca pudesse ser um best-seller. É uma espécie de curiosidade literária. Está muito construído 
na base de referências literárias, a primeira é logo a figura de Fradique, depois há referências aos meus antecessores, a todos os meus antecessores, com uma porção de interferências de segunda ordem, que não são dos meus antecessores, que são criação minha. Outro elemento meu são os tais "esquemas", uma espécie de diário que ele teria escrito, e isso é realmente invenção, mas também uma maneira de dar interesse ao romance, mais do que só as aventuras dessas quatro ou cinco personagens principais, o neto e a neta, depois há o "eu", e há um amigo dele, aquele Baltazar Touriga, depois há uma personagem próxima ao protagonista que é uma amiga que ele tem pelo ponto de vista profissional e há depois a namorada, são duas figuras bastante apagadas. Portanto, eu inventei essa história dos "esquemas", umas indicações mais ou menos técnicas que o Fradique tinha, e que poderiam servir de base para uma autobiografia sua. Digamos que o meu Fradique é demasiado complexo para o leitor comum. Nunca poderia ser um romance popular, e nem foi essa propriamente minha intenção. Foi mais uma espécie de prolongar o jogo, um jogo magnífico, um jogo fascinante. Tive sempre muito apoio do meu jovem editor, Manuel Vieira da Cruz, que foi sempre um grande fã do meu Fradique, desde o começo do livro, desde o absoluto começo do livro, porque foi ele que me desafiou pra escrever um romance com o Fradique como objeto. É realmente uma pessoa muito competente no ramo de edição.

E. M.: Agora uma pergunta específica sobre o romance: No final do seu texto, deu-me a impressão de que Martinho e o colega, ao invés de entrar na sala e incomodar os descendentes de Fradique, vão andar pela cidade. Pois bem, a minha impressão foi que era uma data de festa civil, mais especificamente uma comemoração de 25 de abril. Isso realmente acontece?

F. V.: Isso acontece. Trata-se do dia 25 de abril de 1999, no momento em que se comemora o $25^{\circ}$ aniversário da revolução de abril. Mas se vir a data que está no fim do romance, a data é de março. Portanto, há uma impossibilidade metafísica, digamos, de ele descrever aquela noite antes de ela acontecer. Houve, de fato, na noite de 24 pra 25 de abril de 1999 uma grande festa na Praça do Comércio, ou Terreiro do Paço, e juntou-se lá uma imensa multidão pra ver fogos de artifício. E os dois, o protagonista e o Balto, avançam a pé, desde muito longe, com muita gente que se dirigia para essa grande concentração na Praça do Comércio. É uma espécie de apoteose, eu quis terminar o romance numa apoteose "real". Entretanto, na avenida Gago Coutinho, a avenida que vai para o aeroporto, no outro extremo da cidade, dá-se o encontro entre dois fantasmas, o neto e a neta de Fradique. E é exatamente porque são fantasmas que os menos fantasmas, o protagonista e o Balto, não entram em contato com eles e os deixam em sua irrealidade. É um jogo narrativo onde há todo esse relacionamento complexo entre realidade e ficção. Tudo é ficção. Mas alguma é menos "irreal” do que a outra. 